\title{
Caput femoris intruded into the pelvic cavity through the apertura ischiadica by congenital luxation of the hipjoint
}

by

\section{Dr. L. SEVERIN PETERSEN.}

Bergen.

The congenital luxation of the hipjoint has as a rule no great influence on the pelvis as a birth-duct. The pelvis becomes as a rule somewhat flat and also widened in the frontal diameter both in the upper aperture and in the exit.

I have never seen mentioned, that caput femoris by this disease has been forced into the cavity, and that in such a way, as perhaps to form a hindrance to the birth.

However I have observed two cases, where this was to be recognized both by means of palpation and with Röntgen rays.

I. 20 years old. I gravida. She was examined in the third month of the pregnancy. Luxation of hip on both sides. The pelvic cavity was felt to be of normal space; but when she lies in the usual position for examination with the thigh in flexion and abduction, one can feel on both sides of the sacral bone, behind spinae ischii, a hemispherical body, that protrudes into the cavity and diminishes the transverse diameter. With straightening of the thigh and adduction the bodies disappear. This phenomenon was verified by a colleague.

The mobility in both joints was good, perhaps the abduction a little diminished.

She gave birth at the right term, the delivery being completely normal and easy. The last part of the second period was however more painful than usual. 
The puerperium was normal. After she had left her bed, there was no more difficulty in walking than previously. She was Röntgened four weeks after the birth.

II. 41 years old. I para. Hip-luxation on both sides. The two capita have slipped somewhat high up. The mobility in the hips is good except for abduction, which is somewhat diminished. She was examined during labours. Also in her case were found the same conditions; if she lies on her back with the thighs bent and abducted - that is as usual in giving birth - one could feel caput femoris on both sides protrude into the pelvic cavity by the side of the os sacrum. She was delivered in breechposition. The birth lasted a long time, $411 / 2$ hours, but this was due to the length of the first period, whilst the passage of the foetus through the pelvis did not seem to be retarded, the usual delivery of the child's shoulders and the head not causing any practical difficulty.

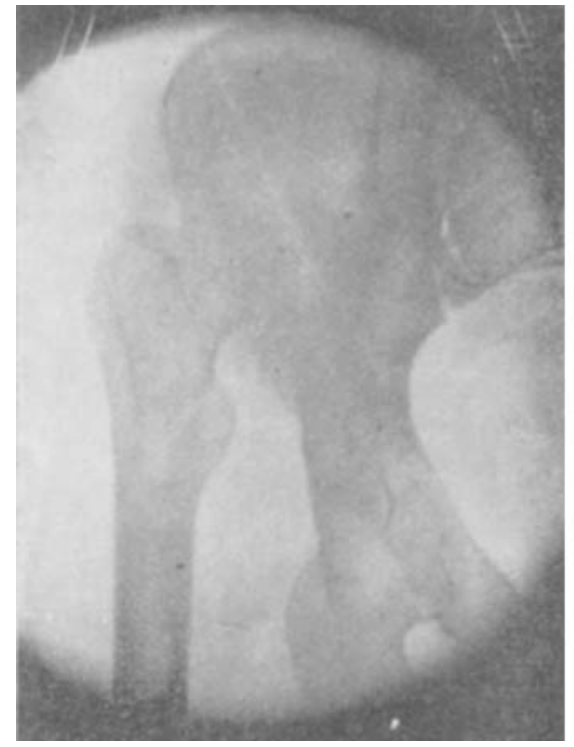

Right hip, extension

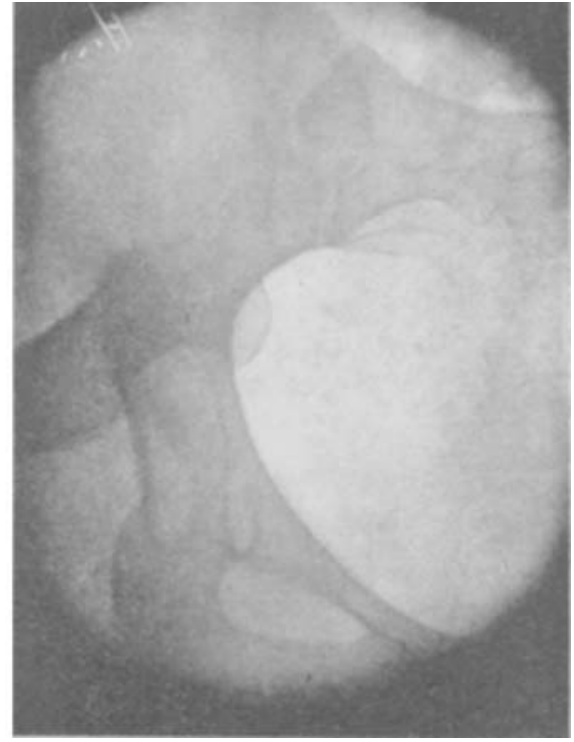

Right hip, flexion and abduction

Unfortunately she could not be $R$. rayed.

On the R. photographs of the first case both capita femorum are seen to be high up on the back of the ossa ilei, when the leg is straightened. - Both the heads of the thighbones are small. The right one has regular contours, whilst the left, which also is the smaller does not show regular lines.

The photographs of the left hip in flexion and abduction showed nothing 
distinctly. During the posing for photographing the head could be felt to intrude, but that did not appear on the plate.

The photograph of the right side, on the contrary, distinctly shows, that the caput femoris is intruded into the cavity, so that more than a quarter of its perifery is seen inside the linea innominata. In my judgment about half the caput could be intruded and reach about $11 / 2-2 \mathrm{~cm}$ into the cavity.

The observed intrusion must pass through apertura ischiadica major. The most important feature in the anatomy of this opening is that it is divided by the pyriform muscle into two halves. The muscle arises inside on the os sacrum and is inserted on trochanter major. Trough the lower and greater opening passes amongst others the nervus ischiadicus, whose plexus lies on the inner surface of the muscle.

Now I think that the following takes place: When the luxated thigh-bone slips up on the back surface of the os ileum, then the pyriform muscle is drawn upwards, and thereby the connective tissue which fills up around the other nerves and vessels in the opening is stretched. When the thigh is bent and abducted, the head of the thighbone slides down over the rim of the aperture and into the opening. One could feel how it slipped over the edge. It becomes indeed a kind of "reposition", but in the wrong place.

The caput femoris must push the muscle and the sacral plexus forward. It was a striking fact, that the intrusion itself did not cause essential pains, but pressure on the heads from inside was very painful.

Although, with such intrusion of the caput into the pelvis, there really occurs a narrowing of the cavity, it seems however, that it does not bring much trouble during labour. This is easy to explain. The heads of the bones are not fixed in this position and the connections are loose. The child will thus be able without great difficulty to push them aside.

When the birth proceeds without the use of narcotics, the woman will instinctively hold the legs in the position, where the pains are small. A slight straightening and adduction of the thighs will cause the heads to slip out again. It will be otherwise, when the birth proceeds under narcotics in dorsal posture, e. g. by the use of an somewhat high forceps. If then one is not attentive to the conditions, there may occur a real obstacle to the passage of the child's head, 
and one must then remember that the plexus sacralis may be exposed to a very severe pressure.

Whilst there is now a practical agreement, that the pelvis by congenital luxation of the hip as a rule has plenty of room in the transverse diameter, Hueter \& Lossen quote Cruveilher as having supposed a considerable contraction in the exit of the pelvis. I have not had the opportunity of reading his observation in the original. It may be, that the contraction mentioned by him was caused by the same intrusion, as has been mentioned by me.

I have since had my attention called to these matters, but as the cases do not happen very frequently I cannot say if similar circumstances may be often observed. - In a third case of a woman in labour with hip-luxation the caput femoris could be felt with certainty in the apertura ischiadica, but it could not be pressed in so deeply, that it could be felt to be in the cavity. 